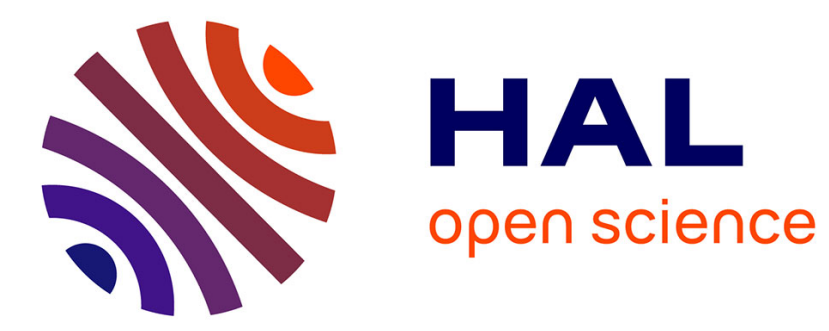

\title{
Organizational Value Creation by IT in Industry 4.0
}

Domonkos Gaspar

\section{To cite this version:}

Domonkos Gaspar. Organizational Value Creation by IT in Industry 4.0. 11th IFIP Working Conference on The Practice of Enterprise Modeling (PoEM), Oct 2018, Vienna, Austria. pp.274-287, 10.1007/978-3-030-02302-7_17 . hal-02156455

\section{HAL Id: hal-02156455 \\ https://hal.inria.fr/hal-02156455}

Submitted on 14 Jun 2019

HAL is a multi-disciplinary open access archive for the deposit and dissemination of scientific research documents, whether they are published or not. The documents may come from teaching and research institutions in France or abroad, or from public or private research centers.
L'archive ouverte pluridisciplinaire HAL, est destinée au dépôt et à la diffusion de documents scientifiques de niveau recherche, publiés ou non, émanant des établissements d'enseignement et de recherche français ou étrangers, des laboratoires publics ou privés. 


\title{
Organizational value creation by IT in Industry 4.0
}

\author{
Domonkos Gaspar ${ }^{1[0000-0002-6083-5742]}$ \\ ${ }^{1}$ Corvinus University, Budapest 1151, Hungary \\ dgaspar@gmx.de
}

\begin{abstract}
At the doorstep of the 4th industrial revolution, standardization and digitalization are high on the agenda of many management boards. With technology having already outpaced organizational development, IT departments may become the engines of the current revolutionary sentiment if they master the transformation of their role and position in the corporate Operations Excellence efforts. CIOs are finding themselves between multiple disrupting fronts: the expectation to be a key driving force in the corporate transformation, while needing to transform their own organization to meet today's challenges, at times when information technology solutions is becoming "everyone's" business in the companies. In this journey the key success factor is the right approach to managing the demand from their customer: the business. This practitioner paper offers a response by reflecting on relevant models, describing an integrated approach and validates certain assumptions based on the experience of a pilot implementation of the Integrated Change Management model.
\end{abstract}

Keywords: Industry 4.0, Digitalization, Change Management, Standardization, Transformation, Operations Excellence, Integration

\section{Introduction and Problem Statement}

Standardization and digitalization are high on the agenda of many management boards. This processes and tools related challenge demands a corporate strategic approach and ownership. It can be argued that the successful management of change is crucial to any organization in order to survive and succeed in the present highly competitive and continuously evolving business environment. However, theories and approaches to change management currently available to academics and practitioners are often contradictory, mostly lacking empirical evidence and supported by unchallenged hypotheses concerning the nature of contemporary organizational change management.

At the doorstep of the 4th industrial revolution, where technology already outpaced organizational development, IT departments may become the engine room of the corporate transformation if they master the transformation of their own role and position in the Operation Excellence efforts. At times where "disruption" is a preferred state of mind, any past models may be questioned on a basic level, and information technology 
solutions become "everyone's" business, should IT departments reinvent themselves, or it is possible to capitalize on past robust practices and still deliver their contribution?

This document provides a possible response from the IT department by reflecting on existing models, further developing them based on experience, to come to the description of a model that had proven itself against the challenges Industry 4.0 put on IT and on the entire organization.

\section{IT in the Lead of the Transformation}

Organizations and processes change dynamically, simultaneously in multiple parts of the organizations, often without coordination, in response to external influence and/or internal needs. These changes almost without exception have a change demand on IT capabilities often impact the same tool/feature(s), eventually causing contradicting requirements. These changes also often join one unified space only in information technology, making the volume and extent of the diverse changes in the organization visible in IT.

In the age of the 4th industrial revolution, organizational units are targeted directly by providers with appealing, sophisticated solutions or look out for new digital capabilities themselves, increasing the demand on the IT organizations twofold: on one hand demand for IT resources internal or external are exceeding capacity/budget, making it necessary for priorization, on the other hand IT organizations struggle to keep structure and harmonized evolution of the IT landscape, for the operation which they will be responsible, at least to a certain degree (even Software as a Service and cloud- based models require safe and multi-faceted connection between the own IT infrastructure and the external solution).

While IT assets often seen only as "enablers" of business, organizational anomalies often manifest firstly in insufficient use of the needed IT tools. More often than justified, the messengers are shot on executive levels, making the inappropriate IT assets and capabilities the reason for those anomalies. While much of the costs, too, for a change are realized in the IT space, the benefits (tangible or intangible) of a successful implementation of a change or a new tool are regularly realized on other parts of the organization.

In response to these challenges CIOs are out on the search for integrative and effective ways to steer requests arriving from their clients, the business. It had been recognized already in the emergence of the reliance on information technology tools, that IT need to align with internal and external domains [1] while remaining/becoming compliant to an ever-increasing number of internal and external regulations and guidelines (eg ISO TS, ISO 17001, external audit, internal audit, COBIT 5, local legal requirements).

We argue that in this circumstance the best defense is to be proactive: the IT organization should learn the motivations and operating systems of its business, reach out and provide it with a commonly recognizable approach to manage changes in an inte- 
grated way. Many IT focused change management models (e.g. ITIL [2]) are well performing in technology related change management but come to their limit in practical use when functional transactional aspects ("business" side) need to be intensively dealt with.

Assumptions. In our work we took certain assumptions which we intended to reflect on following our project:

1. Majority of the IT deliverables fail to perform due to improperly prepared organization (users) or changing requirements.

2. It is possible to develop a model which manages all elements of a successful organizational change implementation. Such a model can be lead out of the IT Department.

3. An integrated approach to change management assures operational sustainability and potentially reduces cost of change.

4. An integrated approach of Systems, Data and Organization should be robust enough to carry business transformation initiatives.

In our article we will elaborate on the context of this initiative. We will also introduce an example for such a structure which relies on theories and methodologies, but tailored and completed for best fit the needs of a globally present mid-size enterprise.

\section{Principles of the Integrated IT Change Management}

\subsection{Background and Relevance}

Background. In order to be successful in finding a common denominator for change management with business stakeholders, IT needs to critically review its own approach and it must reflect on the key models and approaches driving the way of thinking and acting in operations in manufacturing.

The second half of the 20th century changed significantly the landscape of manufacturing management. In the search of more efficient production models, Toyota Motors developed in the '50s and '60s a model [3] that combines attitudes, themes and specific techniques into an integrated socio-technical system for manufacturing. It is commonly referred to as the Toyota Production System (TPS). The LEAN methodology [4] is an evolution of TPS. TPS and LEAN are today the industrial reference in the manufacturing space. It is without exaggeration to state, that every production company developed its own manufacturing system based on the principles of TPS and LEAN. A key common point of these approaches is the establishment of the Continuous Improvement $(\mathrm{CI})$ process as operational initiator of changes. The CI process seeks to progress through "incremental" improvement over time or "breakthrough" improvement all at once by developing and maintaining a self-learning organization.

Among the most widely used tools for CI is a four-step quality model - the plando-check-act (PDCA) developed by Shewhart [5] and enhanced by Deming to the PDSA cycle (plan-do-study-act) [6] through incorporating the idea of deductive and 
inductive (organizational) learning throughout the process. The PDCA cycle has inspired other, broadly recognized industrial approaches [7] and it keeps evolving [8] to adapt to other industries and organizational maturity levels as well.

In order to address the imminent need of strategic alignment between IT and other departments, the Business Process Management (BPM) approach was developed [9] to control software related process changes. BPM focuses on business operations, as well as key value adding and supporting activities of organizations. BPM integrates several methods and techniques for modelling, analyzing, reorganizing, operating and monitoring the processes of an organization. The BPM lifecycle is widely used in IT related projects and it has a potential to be utilized for process improvement as well [10]. Its stages can well be put in relation with the PDCA cycle, providing a potential for common denominator in projects approach with industrial stakeholders.

Table 1. Alignment between the process steps of the Business Process Management Lifecycle and the Shewhart Cycle

\begin{tabular}{|c|c|}
\hline $\begin{array}{c}\text { Business Process Management } \\
\text { Life Cycle }\end{array}$ & Shewhart Cycle \\
\hline Process Documentation & Plan \\
\hline $\begin{array}{c}\text { Process and System Analysis } \\
\text { Implementation and change } \\
\text { management }\end{array}$ & Do \\
\hline $\begin{array}{c}\text { Process Operation } \\
\text { Process Controlling and Moni- } \\
\text { toring }\end{array}$ & Check \\
\hline Business Process Strategy & Act \\
\hline
\end{tabular}

ITIL provides a set of detailed practices for IT service management and focuses on aligning IT services with business needs. Project- and Program management principles commonly used in IT environment, such as PRINCE2 [11] and MSP [12] also provide orientation for change management handling. There is argumentation though, that while they define processes for most relevant information technology related aspects, their governance processes lack the right strategic view for achieving the objectives of the business in the organizations [13] [14]. IT organizational structures, which are tendentially defined by these IT service management frameworks [15] can be an obstacle in efficient engagement with the business stakeholders.

Relevance. To respond adequately to Industry 4.0 challenges, a cross departmental evaluation of opportunities and rethinking of processes is necessary in the enterprises - and beyond. Larger integration of production machinery and other systems requires collaboration between IT and other departments even on areas, which were previously no common domains. While striving for more efficient collaboration within departments should be a constant effort, the current momentum created by Industry 4.0 could be leveraged by the IT departments to rethink their approach for better alignment and 
conclusively more value add collaboration with the business stakeholders. When successful, IT departments will not only be able to co-create the transition of production operations into the new era while keeping their services structured on high level and quality, but more generally, they will be able to maintain their position as key value creator in the organizations. Establishing an improved way for Change Request management may just be the right first step.

\subsection{Integration with Business Process Management}

As mentioned above, the BPM life cycle approach aligned with the company's CI structure is sufficient for a common denominator with the business stakeholders on change management. In this chapter we will expand the theoretic basis with IT change relevant aspects to define a conceptual model which will be referred to later.

We use the model described by Gabor et al. [16] to demonstrate the integration of the IT Change Request processing in an overall BPM model. Our key statement is that an IT change can only be successful, if the related organizational, process and data changes are handled simultaneously in an integrated way. This way the automatism delivered is embedded and can be operated on the required quality level. Many actual cases demonstrate the devastating consequence of not developing to enable the IT technology change when it is delivered.

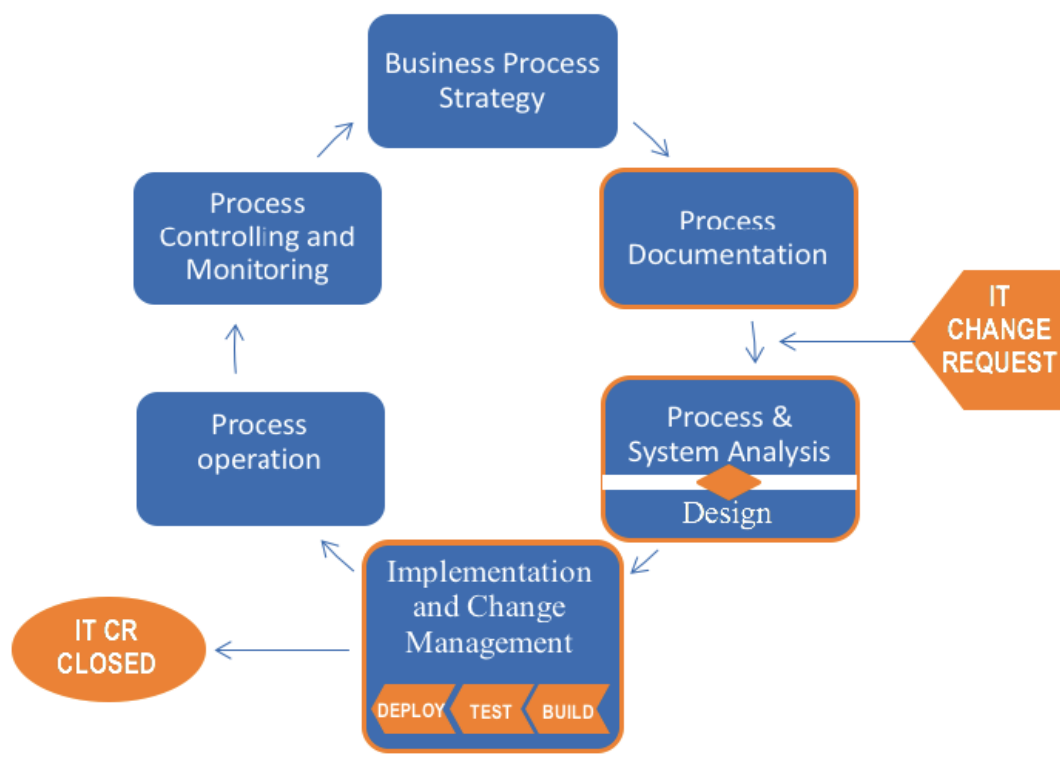

Fig. 1. Business Process Management circle by Gabor et al [16], enhanced with IT Change Management components based on ITIL [2]

In general, we argue, that the BPM model needs to be completed by a decision making point, since in an organization not all alteration to the process are approved consciously 
or practically. We locate the decision making point between analysis of the change requirement and detailed design. The decision making point is the final approving authority for the Change Requests (a.k.a Change Advisory Board, CAB). Should the CAB decline the realization of a Change Request, so it's processing will be aborted and the Change Request either reassigned for further Analysis or it will be closed altogether.

Furthermore, we made the following extensions to the model to assure an integrated approach:

- Process description must include description of the used IT tools. Appropriate documentation of processes and system use are prerequisites for integrated IT Change Request management. This point will be further discussed in chapter 5.2.

- IT Change Requests will be included in the loop before the Analyze and Design stage so that they can be included in the following stage.

- Analysis and Design must be made in an integrated way. The decision making point contains the total cost of the Implementation and Change Management: Processes, Data and (IT) Systems.

- Implementation and Change Management will contain the process and data related changes, but this phase also covers (IT) System activities. These are commonly broken up into Build, Test \& Accept and Deploy phases.

- Upon successful implementation of the IT CR, it is closed and the process is lived with standard level of supports on Process as well as IT side

\subsection{Knowledge Management}

Knowledge management is a key element in assuring the sustainability of the implemented process. Experience shows, that processes and related benefits do not get fully realized and/or erode if knowledge management is left to the software training only. Knowledge management drives organizational learning which takes place during the entire Business Process Management lifecycle. A conscious approach to knowledge management improves efficiency of implementation of a change and the maintenance of the result of the change. Our integrated Change Management approach is addressing knowledge management on multiple layers:

- It assumes the existence of a base line: a complete operational map, organizational template and enablement infrastructure (including continuous improvement and lessons learned initiatives) to perform the tasks as defined

- By analyzing the complete impact of a change, adjustment in knowledge is also mapped out and addressed in trainings

- It places the Change Request process into the company's process map, assuring that also this process would benefit from the organizational learnings the company develops.

\subsection{Integrated Approach to the Change Elements}

IT Change Management is often understood purely in IT context: build new functionality, test, train and deploy. I argue that the approach needs to distinguish between the 
following domains, and involve impacted business domains. Changes in any of these domains need to be planned and followed up individually in an integrated way. Although they might be achieved in common steps (eg training new process and system usage), they have their specifics. The below categorization distinguishes among those key elements.

Table 2. Overview of the change elements

\begin{tabular}{|l|l|l|}
\hline \multicolumn{1}{|c|}{ Element } & \multicolumn{1}{|c|}{ Purpose } & \multicolumn{1}{|c|}{ Typical Content } \\
\hline $\begin{array}{l}\text { Organization and } \\
\text { process }\end{array}$ & $\begin{array}{l}\text { Definition of business pro- } \\
\text { cesses and the organizational } \\
\text { aspects (e.g. organization } \\
\text { structure, roles, skills) to per- } \\
\text { form the process }\end{array}$ & $\begin{array}{l}\text { - Business Process Design } \\
\text { Embedment of the Change Re- } \\
\text { Euest process into the process } \\
\text { Execution Capacity con- } \\
\text { siderations }\end{array}$ \\
\hline landscape of the organization
\end{tabular}

Our experience shows that the above view is simple yet complete in identifying and combining the key domains impacted by a change in the current digital era and that in its simplicity it helps communicating the approach to any stakeholder organization. The domains may be further broken down though (e.g. People, Organization, Processes within Organization and process; Information Technology, Controls Technology within Systems) if scaling requires. The integrated nature assures a maximization of the benefits expected from the change by i) reducing collateral damage caused by omitted aspects of interrelated processes; ii) securing ROI through good control of total cost of the Change implementation; iii) potentially reducing Systems changes by enabling a business side solution. 


\section{Description of the Integrated IT Change Request Process}

The described integrated IT change request management process model was developed as a trial and implemented in a globally active Tier 1 Automotive supplier.

During the development of the model the frequent scenario was considered, where a new process, task, or data flow is often not possible to test without the readiness of the supporting system. Therefore, from the Phase "Build" onwards the model merges the three elements into one course of action.

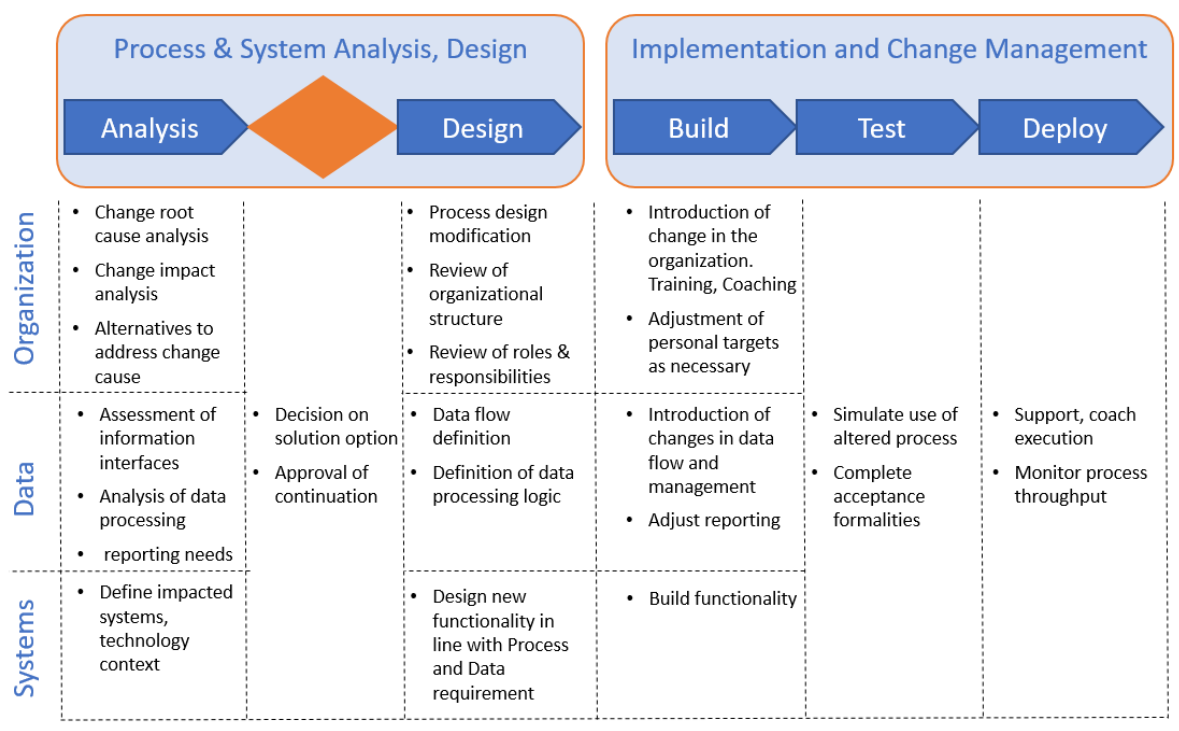

Fig. 2. Integrated IT Change request process (own work)

Workshops during the implementation phase indicated that the defined approach is useable with "agile" and with "waterfall" delivery models alike, with little adaptation, although hereto further studies are needed. Due to its role based approach companies of different size and management models can find it applicable.

\subsection{Roles and Responsibilities, governance bodies}

Key enabler of process efficiency as well as knowledge management is the clear and transparent allocation of the roles and responsibilities among the stakeholders. The above Change Request process contains new tasks and assumes new responsibilities, which need to be allocated to assure process sustainability. Due to its integrated nature, there is a broad range of stakeholders needing to input in the process, however their contribution may be timely and content-wise limited. This makes the justification of the creation of new jobs for the purpose of a Change Request challenging and partially dis-proportional. 
Well known management approaches [8] as well as new disciplines [17] suggest to define roles that can be sized and assigned to people (one person can have multiple roles) rather than jobs, in order to make the model universally applicable in different delivery and management methodologies.

- To assure scalability for the implementing organizations, the model uses the rolebased approach. In that sense it distinguishes between

- Individual contributor roles, which are embodied by one person or a group of persons with the same skillset, such as Change Requester, Business Relationship Manager, Change Manager, Release Manager, Competence Center (CC) Leader, Delivery Manager, Release Manager.

- Governance Bodies, which are group of people with differing skillset and responsibility. Governance bodies hold regular, formalized meetings for alignment and/or decision making. Governance bodies in the Changer Request process are: Delivery Alignment Meeting (DAM) and the most important decision making instance: the Change Advisory Board (CAB)

These decisions for role based approach proved to be very useful in the implementation.

\subsection{Process KPIs and Reporting}

Our change request model is intended to manage a large number of Change Requests simultaneously. In order to enable steering of the process, following basic KPIs are predefined and reported in regular intervals:

- Volume evolution trend - demonstration of Change Request volumes per status through multiple periods. It visualizes momentum and identifies bottlenecks in the process

- On Time Delivery (OTD) - The \% of changes that are delivered to Test and Acceptance according per plan or earlier. This KPI monitors the throughput reliability of the domains building the solution (process, data, and systems). Bottlenecks can be identified.

- On Time Release (OTR) - process flow KPI demonstrating the reliability of the planning and robustness of all participating organizations in realizing the Change

- First Time Right (FTR) - KPI for quality monitoring of the technical components: $\%$ of changes whose technical release was successful for the first attempt

\section{$5 \quad$ Implementing and Maintaining the IT CR Process}

The Company, a global Tier 1 automotive supplier headquartered in Winterthur, Switzerland, with worldwide 50+ plants, and more than 12 thousand employees. It operates in four highly independent business units. Information Technology (IT) is a centrally located function, supporting 150+ applications locally, regionally and globally. It services all business groups as well as promotes standardization, in Technology and beyond. In 2015 the Company's management requested IT to expedite standardization both in IT assets as well as in the "way of working". The Company's IT Department 
decided to implement the here described integrated IT Change Request management model.

\subsection{Preparation}

After initiation of the project, the model was introduced and the scope and context of the IT Change Request management process was defined. The process was to be upand-running in 6 months' time.

- Scope: As per management intention, the process had to cover all IT assets, and needed to integrate with the existing Business Process Governance Body.

- Context: the initial study showed that although $100+$ people belonged to the global IT organization, there was neither central information for the Change Request volumes and costs, nor structured decision making and planning. Due to lack of prioritization globally, it was uncertain if the IT organization is spending its resources efficiently.

Once the integrated change request model was introduced and approved by the leadership team in the IT community, the concept was carried to the major stakeholders, influencers, and members of the Business Process Governance Body. The IT CR process was strategically placed within the service offering of IT.

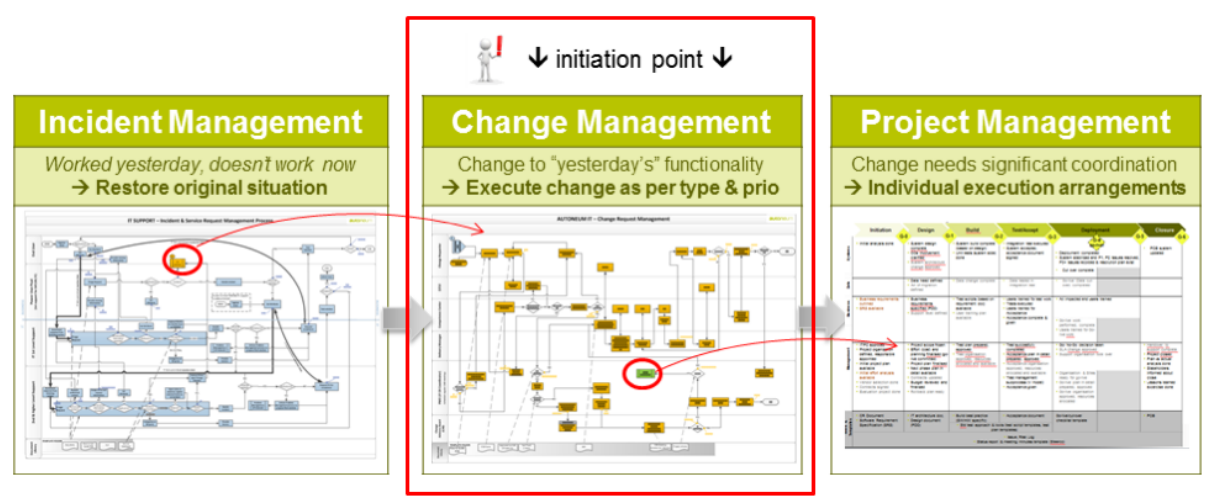

Fig. 3. Service architecture of the IT department (own work)

A Workgroup was created to define the needed categorizations and groupings (e.g. Software-wise, Process categories), define schedule and agenda of the recurrent events and allocate process roles formally. The job of the Workgroup was completed in 12 weeks.

\subsection{Implementation}

Following positive decision from all stakeholders, the implementation work focused on 3 major tracks: 
- Process definition and training of stakeholders. User group focused training courses were developed and delivered to small groups. Trainings were interactive class-room trainings provided in person or on line. Altogether, until the end of the implementation, 67 units of trainings were delivered.

- Establishment of legacy - we intended to start the process with all open Change Requests in one database. This required a large amount of data scouting (finding all registers of change requests, if any existed) and data cleansing to bring the information into the same format. The process started with 138 Change Requests, and by the end of the first 8 weeks the number of CRs were 271.

- Set up the Change Request Management software. Following successful functional tests, agreed categorizations needed to be entered, legacy Change Requests migrated, users created and user rights assigned. The team decided to utilize the already existing, but only partially used Change Management tool.

September 2015 marked the start of the IT Change Request process. In order to manage expectations a 2 months "grace" period was introduced, since it was impossible to simulate organizational reactions to the new process and initial adjustments could have been necessary. Finally, 3 months after the start of use of the Integrated Change Request process, the implementation project was closed with general satisfaction of stakeholders and the management team alike.

As of 2018, the Change Request process is still in use in the Company, with a history of more than 500 open and closed change requests.

\subsection{Lessons learned}

The project ended successfully and it enriched the organization with key learnings which can be used to improve the model and the implementation recommendations:

1. Stakeholders provided a very positive feedback on the structure of the Change Request process. It had met a long existing need - this is one of the explanations for the "explosion" of the numbers of the change requests especially in the first months.

2. The role based responsibility approach prove to be the only feasible approach to make sure that the broad range of stakeholders are formally engaged, without the need of new recruitment on those positions. It also helped to engage the most adequate persons for each task - if it was necessary we split roles for this purpose.

3. Training of the user groups revealed that certain underlying clarifications with line management needed to be made. Resistance for change was also a hurdle that the trainers needed to overcome with special skills and support from management.

4. Positive feedback was countered by lack of free capacity on long term during the learning phase, therefore c.a. $60 \%$ of the training units needed to be repeated.

5. Process KPIs were very useful to steer the process velocity, as bottlenecks became visible, fact-based countermeasures could be introduced. Due to their similarity with manufacturing operational KPIs, they could be easily understood by non-IT stakeholders as well. 
6. CRs implemented according to the model had tendentially a smoother acceptance in the organization. Rework on implemented CR remained low (no historic data from before the model, the statement is based on feedback from the requestors)

7. The actual CRs brought to light that the assumed process base-line in the company is incomplete. A recovery plan was launched outside the IT CR implementation project.

8. Multiple Change Requests did not reach realization phase. The process responsible persons stopped them (in defense of standards) and/or provided a process based solution without need for Software change.

9. The CR process proved to be a good initial filter for Industry 4.0 related projects. It facilitated common thinking and evaluations of the actual value add of a new technology in the organization.

In recognition of the strength of the backbone that the ITCR process provides, and due to the increasing volumes, in 2017 the IT leadership decided to orientate its teams according to the structures of the IT CR process, and created the role of Service Deliver Responsible in each IT sub-department.

\subsection{Applicability for managing Industry 4.0 related changes}

The same Company initiated its Industry 4.0 thought process in 2016, and as a consequence, in early 2017 the first Industry 4.0 related change requests were registered. Many of the process stakeholders were not aware that the actual change requests were related to Industry 4.0 - their bare recognition was that the requests were not ordinary and they needed a large amount of conceptual considerations as well as process impact was larger than usual.

In case the impact assessment could not be done within a reasonable effort, or the necessary anticipations could not be done as expected, under the phase of Analysis, Proof of Concepts $(\mathrm{PoC})$ were conducted and the result of these were integrated back into the Analysis considerations.

All change requests had been processed according to the process. Change requests with large efforts were categorized projects thus moved outside the Change request process. The remaining Change requests, as of 2018 these were over 20, were processed and delivered in good quality and under control.

In an Industry 4.0 context the IT Change Request process leveraged its thorough integration of organizational and data aspects, and prove to be a solid mean to address the special needs of Industry 4.0 initiatives.

The robust handling model of IT had been recognized by high management of the company, and as a result, IT became a driving force in the Industry 4.0 transformation initiative. 


\section{Conclusion}

A single case study is not sufficient for quantitative conclusions, yet it allows qualitative conclusions that can be indicative for organizational change practitioners and IT departments seeking for improvement in their engagement with the operational stakeholders.

The development of our integrated IT Change Request process started with some basic assumptions, as described in Chapter 2. These assumptions could be validated during the piloting use of the model. Herewith we refer to them:

1. ASSUMPTION: Majority of the IT deliverables fail to perform due to improperly prepared organization (users) or changing requirements.

FINDING: Confirmative. The inclusion of Organizational and Data aspects in the Change Request model, Change Request delivery became more successful and appreciated.

2. ASSUMPTION: It is possible to develop a model which manages all elements of a successful organizational change implementation. Such a model can be lead out of the IT Department.

FINDING: Confirmative. The integrated IT Change Request process covers all domains of organizational change. The model is recognized by all stakeholders. Most important constraint for the Leadership of the model is understanding of requirements of all stakeholders, and seeing the Change Requests as part of a business change. It is even well positioned to build up and lead such a cross-functional model.

3. ASSUMPTION: An integrated approach to change management assures operational sustainability and potentially reduces cost of change.

FINDING: Partially confirmative. The change request process covers all important elements to assure seamless integration. Cost of change went through a perceived reduction, although the total effort the organization needs to invest into Change Management had increased due to the more intensive involvement of other domains ("business side stakeholders"). Through the provided transparency stakeholders and managers see resources spent on Change Requests as "good investment"

4. ASSUMPTION: An integrated approach of Systems, Data and Organization should be robust enough to carry business transformation initiatives.

FINDING: Confirmed. The recent use of the IT Change Request process for Industry 4.0 related initiatives confirmed that the model is capable to manage any kind of organizational changes regardless the proportion of system changed associated. Through this it had also been confirmed, that with the right approach, an IT organization can be a central driving force for Industry 4.0 or Digitalization transformations

The current attention to Industry 4.0 might historically prove to have been a hype. Nevertheless, it is currently reshaping the landscape of intra-organizational collaboration. Some of those changes will institutionalize, especially the impact made by stronger collaboration among traditionally separated specialist domains such as IT, CT (Control 
Technology of machines) and Production Systems. Conclusively, highly integrated approach to change management, such as the example described in this paper, will remain a key vehicle for sustainable organizational value creation. It also bears the opportunity for IT departments to remain, independently of the respective current trend, in the center of gravity for value creation in operations.

\section{References}

1. Henderson, J. C.; Venkatraman, N. (1993). „Strategic Alignment: Leveraging Information Technology for Transforming Organisations". IBM Systems Journal, 32(1), pp.4-16

2. SMME (2009): ITIL V3 Foundation - Student Manual; Ver 5; pp 234-272; Leuven

3. Ohno, Taiichi (1988). Toyota Production System: Beyond Large-Scale Production (English translation ed.). Portland, Oregon: Productivity Press. pp. 75-76. ISBN 0-915299-14-3.

4. Womack, James P.; Daniel T. Jones; Daniel Roos (1990). The Machine That Changed the World. ISBN978-0-7432-9979-4

5. W. A. Shewhart; Statistical Method from the Viewpoint of Quality Control; Dover Publ., New York 1986, ISBN 0-486-65232-7, S. 45.

6. Deming, W. Edwards (1993). The New Economics for Industry, Government, and Education. Boston, Ma: MIT Press. p. 132. ISBN 0262541165.

7. Tennant, Geoff (2001). SIX SIGMA: SPC and TQM in Manufacturing and Services. Gower Publishing, Ltd. p. 3-4. ISBN 0-566-08374-4.

8. Moen, Ronald; Norman, Clifford. "Evolution of the PDCA Cycle" (PDF). Retrieved 12 February 2017

9. Scheer, A.-W.; Abolhassan, F.; Jost, W.; Kirchmer M. (2002): Business Process Excellence - ARIS in Practice, Springer http://dx.doi.org/10.1007/978-3-540-24705-0

10. Josic D (2016); Kritische Analyse der Prozessoptimierung als wesentliches Element des Change Managements; München; GRIN Verlag

11. Berry D., Atkins WS., Allen P. (1996): Managing successful projects; pp 251-291; London; TSO Publishing

12. Sowden R. et al. (2007): Managing successful programmes; pp 47-75; London; TSO Publishing

13. Alonso, I.A.; Verdún, J.C; Caro, E.T (2017): Description of the structure of the IT demand management process framework; International Journal of Information Management Volume 37, Issue 1, Part A, pp 1461-1473

14. Rahimi, F; Møller, C; Hvam, L (2016): Business process management and IT management: The missing integration; International Journal of Information Management; Volume 36, Issue 1, pp. 142-154

15. Marrone M, Kolbe L (2011) Einfluss von IT-Service-Management-Frameworks auf die ITOrganisation. Wirtschaftsinformatik 53(1):5-19

16. Gabor, A; Ko, A; Szabo (2015). Corporate Knowledge Discovery and Organizational Learning pp. 6-23; Heidelberg: Springer Verlag

17. Robertson, B; Thomison, T (2015): "Holacracy - discover a better way of working". White Paper, HolacracyOne, LLC, Spring City, PA, pp.1-10 